NASA/TM-2007-214806

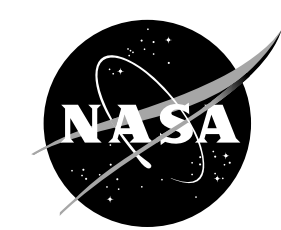

\title{
Development of Advanced Stirling Radioisotope Generator for Space Exploration
}

Jack Chan

Lockheed Martin Space Systems Company, King of Prussia, Pennsylvania

J. Gary Wood

Sunpower Inc., Athens, Ohio

Jeffrey G. Schreiber

Glenn Research Center, Cleveland, Ohio 


\section{NASA STI Program . . . in Profile}

Since its founding, NASA has been dedicated to the advancement of aeronautics and space science. The NASA Scientific and Technical Information (STI) program plays a key part in helping NASA maintain this important role.

The NASA STI Program operates under the auspices of the Agency Chief Information Officer. It collects, organizes, provides for archiving, and disseminates NASA's STI. The NASA STI program provides access to the NASA Aeronautics and Space Database and its public interface, the NASA Technical Reports Server, thus providing one of the largest collections of aeronautical and space science STI in the world. Results are published in both non-NASA channels and by NASA in the NASA STI Report Series, which includes the following report types:

- TECHNICAL PUBLICATION. Reports of completed research or a major significant phase of research that present the results of NASA programs and include extensive data or theoretical analysis. Includes compilations of significant scientific and technical data and information deemed to be of continuing reference value. NASA counterpart of peer-reviewed formal professional papers but has less stringent limitations on manuscript length and extent of graphic presentations.

- TECHNICAL MEMORANDUM. Scientific and technical findings that are preliminary or of specialized interest, e.g., quick release reports, working papers, and bibliographies that contain minimal annotation. Does not contain extensive analysis.

- CONTRACTOR REPORT. Scientific and technical findings by NASA-sponsored contractors and grantees.
- CONFERENCE PUBLICATION. Collected papers from scientific and technical conferences, symposia, seminars, or other meetings sponsored or cosponsored by NASA.

- SPECIAL PUBLICATION. Scientific, technical, or historical information from NASA programs, projects, and missions, often concerned with subjects having substantial public interest.

- TECHNICAL TRANSLATION. Englishlanguage translations of foreign scientific and technical material pertinent to NASA's mission.

Specialized services also include creating custom thesauri, building customized databases, organizing and publishing research results.

For more information about the NASA STI program, see the following:

- Access the NASA STI program home page at http://www.sti.nasa.gov

- E-mail your question via the Internet to help@sti.nasa.gov

- Fax your question to the NASA STI Help Desk at 301-621-0134

- Telephone the NASA STI Help Desk at 301-621-0390

- Write to: NASA Center for AeroSpace Information (CASI) 7115 Standard Drive Hanover, MD 21076-1320 
NASA/TM-2007-214806

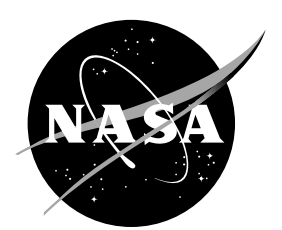

\section{Development of Advanced Stirling Radioisotope Generator for Space Exploration}

Jack Chan

Lockheed Martin Space Systems Company, King of Prussia, Pennsylvania

J. Gary Wood

Sunpower Inc., Athens, Ohio

Jeffrey G. Schreiber

Glenn Research Center, Cleveland, Ohio

Prepared for the

Space Technology and Applications International Forum (STAIF)

sponsored by the Institute for Space and Nuclear Power Studies at the University of New Mexico Albuquerque, New Mexico, February 11-15, 2007

National Aeronautics and

Space Administration

Glenn Research Center

Cleveland, Ohio 44135 


\section{Acknowledgments}

The work described in this paper was performed for the Department of Energy and for the Science Mission Directorate Radioisotope Power System Program, which provided funding for these projects. The authors wish to acknowledge the contributions made by the Advanced Stirling Radioisotope Generator (ASRG) team members from Lockheed Martin

Space Systems Company (D. Tantino, D. Hill, T. Kull, D. Leland, J. Priest, and D. Kuhlman), Sunpower Inc.

(J. Crawford, A. Buffalino, and D. Keiter), the Thermal Energy Conversion Branch of NASA Glenn

Research Center (W. Wong and R. Shaltens), and DOE (R. Richardson).

This report is a formal draft or working paper, intended to solicit comments and ideas from a technical peer group.

This report contains preliminary findings, subject to revision as analysis proceeds.

Trade names and trademarks are used in this report for identification only. Their usage does not constitute an official endorsement, either expressed or implied, by the National Aeronautics and Space Administration.

Level of Review: This material has been technically reviewed by technical management.

Available from

NASA Center for Aerospace Information 7115 Standard Drive

Hanover, MD 21076-1320
National Technical Information Service 5285 Port Royal Road Springfield, VA 22161 


\title{
Development of Advanced Stirling Radioisotope Generator for Space Exploration
}

\author{
Jack Chan \\ Lockheed Martin Space Systems Company \\ King of Prussia, Pennsylvania 19406 \\ J. Gary Wood \\ Sunpower Inc. \\ Athens, Ohio 45701 \\ Jeffrey G. Schreiber \\ National Aeronautics and Space Administration \\ Glenn Research Center \\ Cleveland, Ohio 44135
}

\begin{abstract}
Under the joint sponsorship of the Department of Energy and NASA, a radioisotope power system utilizing Stirling power conversion technology is being developed for potential future space missions. The higher conversion efficiency of the Stirling cycle compared with that of Radioisotope Thermoelectric Generators (RTGs) used in previous missions (Viking, Pioneer, Voyager, Galileo, Ulysses, Cassini, and New Horizons) offers the advantage of a four-fold reduction in $\mathrm{PuO}_{2}$ fuel, thereby saving cost and reducing radiation exposure to support personnel. With the advancement of state-of-the-art Stirling technology development under the NASA Research Announcement (NRA) project, the Stirling Radioisotope Generator program has evolved to incorporate the advanced Stirling convertor (ASC), provided by Sunpower, into an engineering unit. Due to the reduced envelope and lighter mass of the ASC compared to the previous Stirling convertor, the specific power of the flight generator is projected to increase from 3.5 to $7 \mathrm{~W}_{\mathrm{e}} / \mathrm{kg}$, along with a 25 percent reduction in generator length. Modifications are being made to the ASC design to incorporate features for thermal, mechanical, and electrical integration with the engineering unit. These include the heat collector for hot end interface, cold-side flange for waste heat removal and structural attachment, and piston position sensor for ASC control and power factor correction. A single-fault tolerant, active power factor correction controller is used to synchronize the Stirling convertors, condition the electrical power from AC to DC, and to control the ASCs to maintain operation within temperature and piston stroke limits. Development activities at Sunpower and NASA Glenn Research Center (GRC) are also being conducted on the ASC to demonstrate the capability for long life, high reliability, and flight qualification needed for use in future missions.
\end{abstract}

\section{Introduction}

This paper presents the developmental status of an electrically heated engineering unit (EU) for Advanced Stirling Radioisotope Generator (ASRG), which is being performed under Phase IIC of the 110-W Stirling Radioisotope Generator (SRG110) program. This program is managed by the Department of Energy (DOE) under NASA's Science Mission Directorate (SMD). The SRG110 as previously reported (Cockfield, 2002) was in the process of fabricating the EU for assembly and test by the Fall of 2006 and was initiating the design of the Qualification Unit using the Technology Demonstration Convertor (TDC). However, with the significant advances in the higher specific power Advanced Stirling Convertor (ASC) demonstrated in the NASA Research Announcement (NRA)-funded project (Wong, et al., 2006), the SRG110 program was redirected in May 2006 to integrate the ASCs into the EU for assembly and test by March 2008 (Misra, 2006). The ASCs will be produced by Sunpower, Inc. in the 
NASA NRA project managed by GRC and delivered to the ASRG program as Government Furnished Equipment (GFE).

One of the key program requirements for this effort is to use as much existing SRG110 hardware as possible, to minimize program cost and schedule. This requirement will limit the effort that can be applied to optimizing the generator design to take advantage of the much reduced mass and envelope of the ASC. The high-temperature MarM-247 heater head being developed in the NRA project also will not be used for the EU. The MarM-247 heater head allows the ASC to operate at $850{ }^{\circ} \mathrm{C}$ with margin, which can improve the conversion efficiency of heat input to AC power output to approximately 40 percent (Wood, et al., 2006a). Instead, Inconel 718, which was the baseline heater head material for the SRG110, will be used as the heater head material in the EU ASRG, limiting the ASC hot-end temperature to no higher than $650{ }^{\circ} \mathrm{C}$.

The use of existing EU hardware with the lower-temperature heater head material will limit the increase in specific power to a lower value than what has been predicted as ultimately possible using the Sunpower ASCs. The primary objective for this phase of the ASRG program is to demonstrate that a highly reliable Stirling system can be built to meet typical NASA mission needs. The EU will be fabricated and tested to a set of typical mission requirements, and its reliability will be estimated using test data obtained over the life of the program. Depending on NASA mission needs, a relatively unchanged generator could be built and qualified for flight, or additional development activity could be pursued in order to further increase the system specific power.

\section{Engineering Unit ASRG Design Description}

The electrically heated EU ASRG design, making use of the existing SRG110 housing hardware, is shown in figure 1. The EU design configuration is very similar to that of the SRG110. It consists of a beryllium housing; two ASCs, each with a dedicated electric heat source located at either end; bulk thermal insulation for multi-mission purposes; an externally mounted active power factor correction controller that is single-fault tolerant; and auxiliary components, gas management valve and pressure relief device, are mounted on the housing surface.

The approach of dual ASC's with each one coupled to an individual heat source prevents fault propagation in the generator in the event of an ASC failure by still allowing one-half generator power output, if desirable from a mission standpoint. The end mounting approach also eases the loading of the radioisotope general purpose heat source (GPHS) modules during generator fueling. It is very desirable to ensure that good thermal contact between the GPHS and ASC hot end exists to minimize temperature gradient and thermal loss. Centrally locating the GPHS modules would make achieving both fuel loading and good thermal contact difficult.

The beryllium housing, which serves as the primary structure, is square in cross-section and is stiffened by axial and lateral ribs. It consists of two halves, one inboard and one outboard, in order to facilitate integration of the ASCs and other internal components during generator assembly. Both inboard and outboard beryllium housings had been fabricated during SRG110 Phase A effort; the outboard housing is shown in figure 2. The reduction in Stirling convertor length from 12.9 in. for the TDC-based design to $7.9 \mathrm{in}$. for the ASC means that the overall generator length can be reduced by $10 \mathrm{in}$. To accommodate this shorter length, only the outboard housing will be used, and a new, shortened inboard housing will be fabricated from an existing spare beryllium billet. Thus for the EU ASRG, the inboard and outboard housings will have unequal length, which will affect slightly the dynamic characteristics of the generator, when mounted in cantilever configuration at the end of inboard housing. The overall dimensions of the EU ASRG are 28.5 in. in length, 18 in. in height, and 11.5 in. in width. 


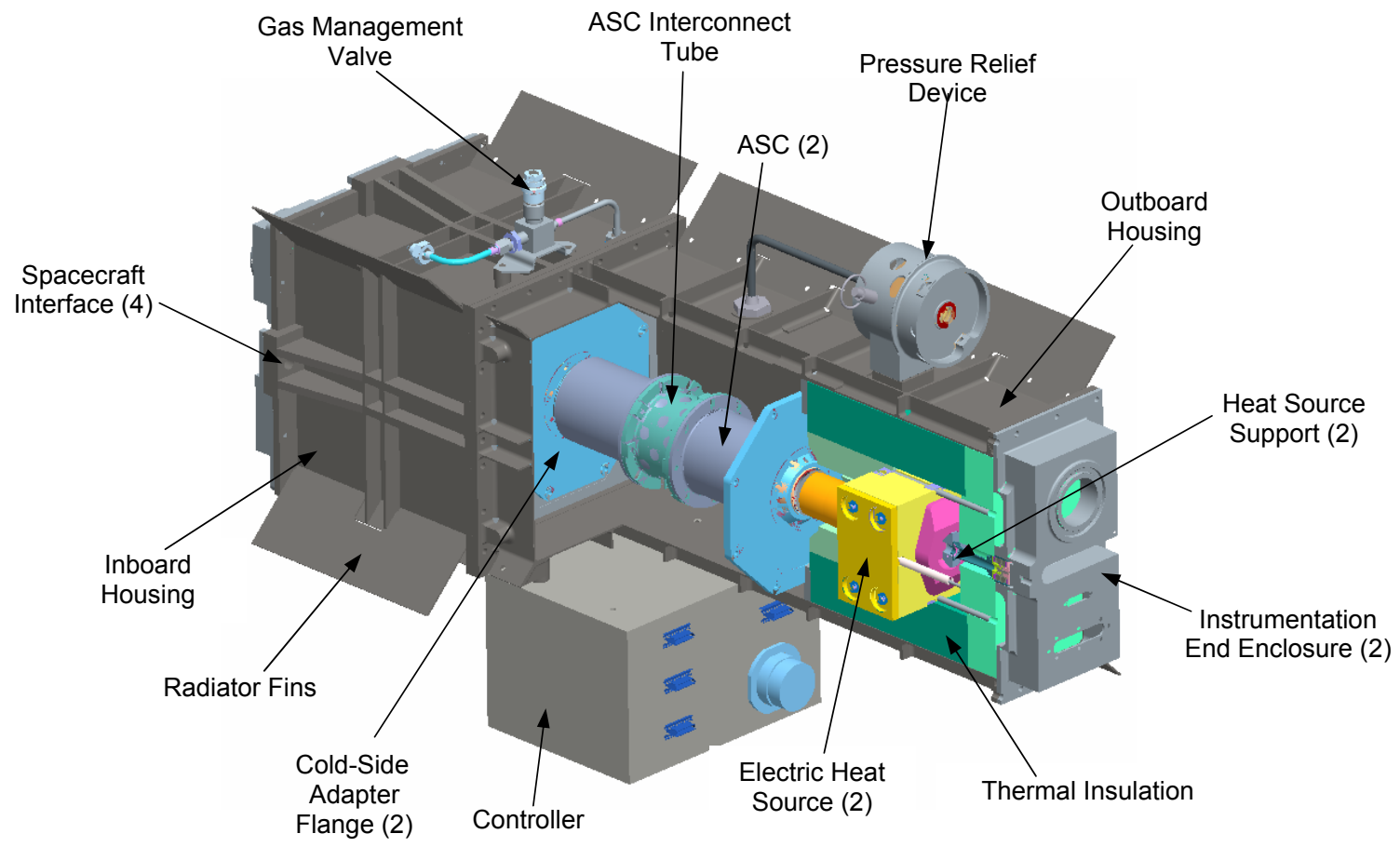

Figure 1.-Engineering ASRG longitudinal section view.

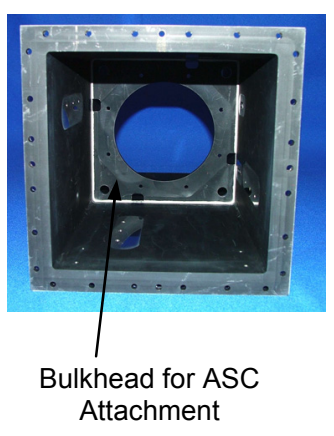

(a) Interior View.

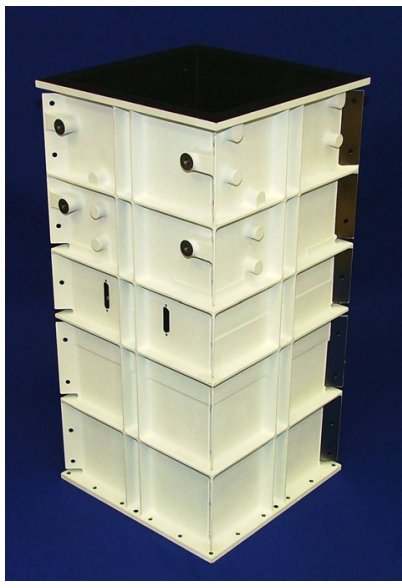

(b) Exterior View.

Figure 2.--Outboard housing for engineering ASRG.

Beryllium fins are sized to provide additional radiative surface area for waste heat rejection. The fins are bolted to four corners along the length of the housing, rather than being attached by brazing, in order to mitigate accidental damage to the fins during fabrication and generator assembly and processing. The effect of fin length on generator specific power is shown in figure 3 . The fins, made from 0.060 -in. thick beryllium, are very lightweight and have a high view factor to space from both sides. As the fin length increases, the ASC rejector temperature decreases, which results in higher generator power output and higher generator mass. Figure 3 shows that the specific power is insensitive to fin length, so the length selection will depend on other factors, such as the need to maintain adequate temperature margin through various phases of a space flight mission, including ground operation and launch, and the desire for a 


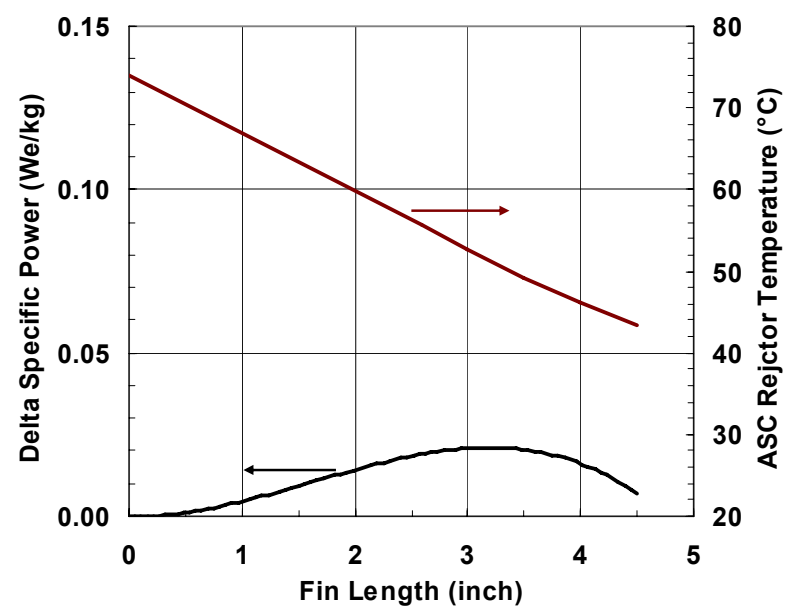

Figure 3.--Radiator fin length trade-off.

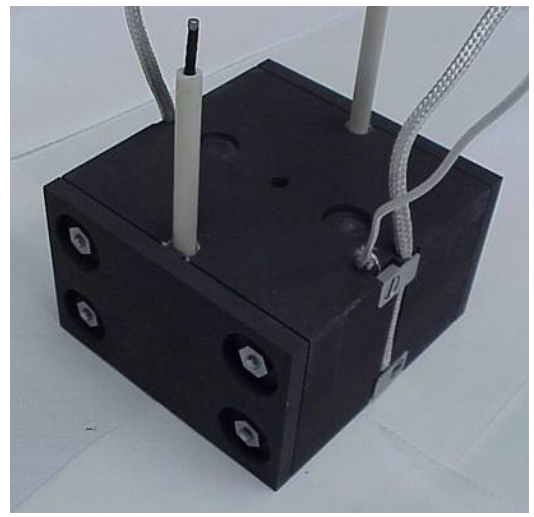

Figure 4.-Electric heat source design.

nominal generator power output for a mission. For the EU ASRG build, the existing 2.6-in. length fins from the SRG110 program will be used.

The electric heat source (EHS) at each end of the EU ASRG is designed to simulate the GPHS for its geometry, thermal characteristics, mass, and dynamic capability so that performance and environmental testing of an electrically heated generator can be conducted. This testing will validate the space flight characteristics of the generator prior to fueling at the DOE facility. The EHS, shown in figure 4, is constructed with two Boralectric (Advanced Ceramics Corporation) heaters mounted to molybdenum ballasts and enclosed within a Poco graphite housing to simulate the fine weave pierced fabric (FWPF) aeroshell of the GPHS. Each EHS has a thermal power capability of $300 \mathrm{~W}_{\mathrm{t}}$, but will be nominally operated at $250 \mathrm{~W}_{\mathrm{t}}$.

The EHS is supported by the end enclosure and by the ASC. The heat source support assembly, consisting of an Inconel stud, a FWPF pressure plate, a zirconia thermal insulator, and spring washers, allows thermal expansion while providing an axial preload that prevents GPHS separation under dynamic loading during launch.

During ground operation and testing, the instrumentation end enclosures are used in place of the flight end enclosures. The instrumentation end enclosures are made from aluminum and contain connectors for EHS power leads and for thermocouples, accelerometers and strain gauges used during testing. Viton o-rings are used to seal the end enclosures against the housing, allowing the interior of the generator to be filled with inert gas during ground operation.

Thermal insulation surrounding the GPHS module and the engine of the ASC consists of a monolithic enclosure fabricated from commercially available Microtherm HT (Microtherm Inc.) insulation. The bulk 
insulation was selected during the SRG110 Phase A effort, rather than multilayer insulation (MLI) as used in the GPHS-RTG, due to the need to operate in the Mars atmosphere for potential multi-mission applications. The Microtherm HT was selected after extensive thermal property testing of coupons versus other insulation materials (Min-K 1400 and Aspen aerogel). Testing was conducted in vacuum, argon and $\mathrm{CO}_{2}$ atmospheres. Microtherm HT was found to have the best combination of low thermal conductivity and low density. Microtherm HT also showed good stability with lowest shrinkage and weight loss after 8,000-hr of temperature exposure in vacuum.

In the event of a failed ASC, the GPHS temperature will increase. Under this condition, the structural integrity of the iridium cladding must be preserved for nuclear safety consideration. Thus, one of the key criteria for thermal insulation selection is its ability to reject GPHS thermal power at a temperature below the point that could cause grain growth in the iridium clad encapsulating the radioisotope fuel pellets. Emergency heat dump tests with Microtherm HT, Min-K, and Microtherm HT/Aspen aerogel combination were performed and all three insulations achieved heat rejection capability below the graingrowth temperature limit by their physical shrinkage and increased thermal conductivity at aboveoperating temperatures.

For the EU ASRG design, an alternate insulation material, aerogel made by JPL, is being investigated to further enhance the specific power potential of the generator. Aerogel has been flown as an insulating material on Sojourner and Mars Exploration Rovers as well as on Stardust for comet sample collection. With a density of $200 \mathrm{~kg} / \mathrm{m}^{3}$, as compared to $350 \mathrm{~kg} / \mathrm{m}^{3}$ for Microtherm HT, significant mass saving can be gained with aerogel. JPL is in the process of formulating the aerogel compositions to achieve a comparable thermal property to that of Microtherm HT. Shrinkage testing at elevated temperature has also been performed that demonstrated the emergency heat dump capability required for ASRG implementation.

The externally mounted gas management valve (GMV) is used to maintain the interior of the generator with inert gas (argon) above atmospheric pressure during ground operations, preventing oxidation of graphite and refractory metal components in the EHS at elevated temperatures. During launch, the barometrically operated pressure relief device (PRD), heritage of the GPHS-RTG design, will be actuated to vent the inert gas to space. For Mars surface application, a vent tube connecting the generator housing to the activated PRD (fig. 1) is sized to provide a reduced gas conductance from the Mars atmosphere to the interior of the generator, such that mass loss of the GPHS graphite aeroshell due to $\mathrm{CO}_{2}$ gasification is insignificant, with no performance impact to ASRG for its 14-year mission life.

The ASCs are mounted to the bulkhead of the housing (fig. 2) via the attached cold-side adapter flanges (CSAF) as part of the integrated ASC design, described in detail later in the paper. ASC waste heat is conducted to the housing and rejected to the environment. With the high ASC alternator efficiency, separate cooling of the alternator is no longer required, which eliminates the SRG110 thermal fins and significantly eases the ASC integration during generator assembly.

\section{ASC Design for Generator Integration}

The ASC to be integrated into the EU ASRG is derived from Sunpower's $88 \mathrm{~W}_{\mathrm{e}}$ design (fig. 5) currently being developed under the NASA NRA project (Wong, et al., 2006). The NRA design makes use of the high-temperature MarM-247 heater head material to allow for operation at $850{ }^{\circ} \mathrm{C}$. At a temperature ratio of 3.1, the efficiency is expected to approach 40 percent (Wood, et al., 2006a). For the EU ASRG, Inconel 718 will be used as the heater head and displacer material replacing MarM-247 and Udimet 720 , respectively, which are required for $850{ }^{\circ} \mathrm{C}$ operation.

The ASC, shown in figure 5, was designed independent of a generator design, with the goals of minimum mass and optimum performance while addressing the reliability of critical components for long-life operation. Limited consideration was given under the NRA project to features required for integration of the ASC into the generator. Thus the first EU ASRG program activities were to evaluate the ASC design and performance characteristics, identify basic external functionality needs for interfaces to the generator, and perform design trade studies for each of these design features. Four features have been 


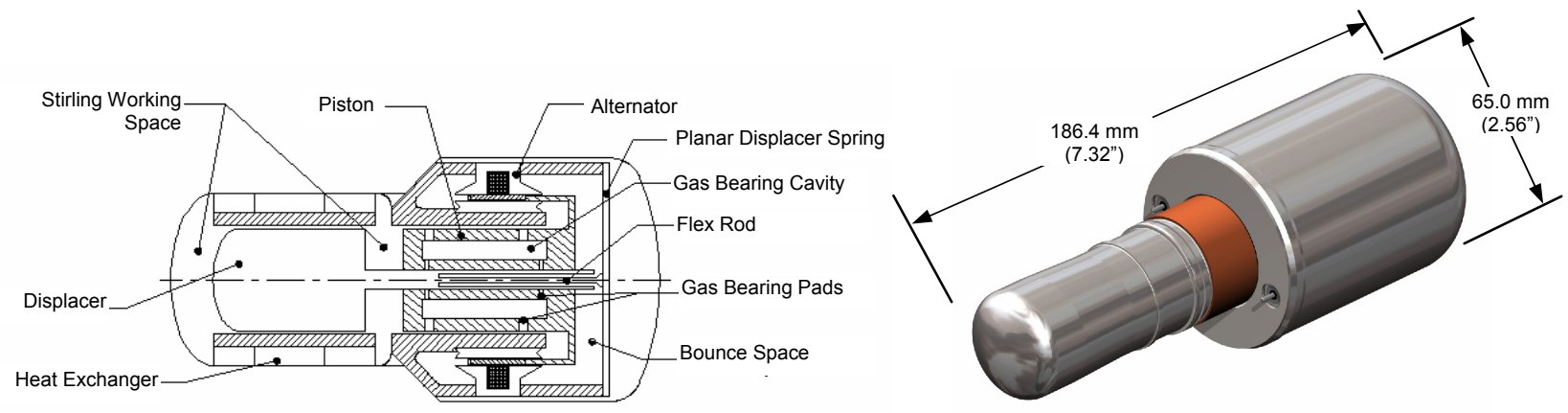

Figure 5.-Features of Sunpower $88 \mathrm{~W}_{\mathrm{e}}$ ASC.

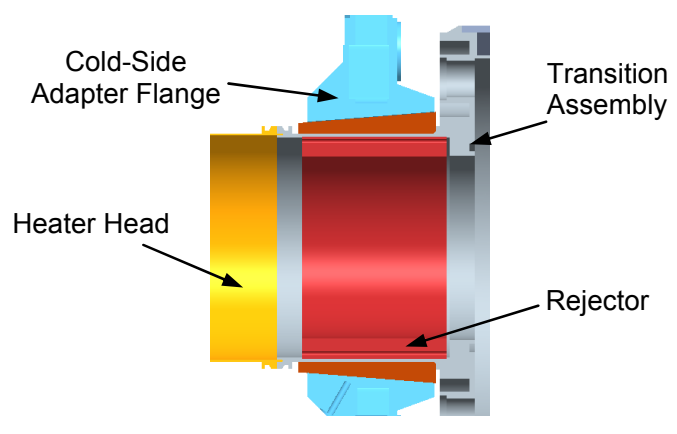

Figure 6.-Cold-side integration design.

identified as basic parts of ASC integration design: 1) heat collector to transfer thermal energy from the GPHS to the hot-end heat exchanger (acceptor); 2) CSAF to remove waste heat from the cold-end heat exchanger (rejector) to the generator housing and which also serves as the structural attachment for ASC; 3 ) integrated piston position sensor for synchronization and control of dual ASCs; and 4) specific connectors for power and instrumentation interfaces.

The heat collector design uses nickel for its compatibility to Inconel 718 heater head, high operating temperature capability, and good thermal properties. With the ASC being smaller in diameter by 0.5 in. and $\sim 40$ percent less in heat exchanger surface area, higher heat flux from the GPHS to the acceptor is expected. This causes a slightly higher GPHS operating temperature, but has the benefit of a lower heat collector mass than that of the SRG110. The ASC is fairly insensitive to acceptor temperature gradient, thus there is no impact to the EU ASRG specific power using the thermal insulation thickness configured for SRG110 housing.

The heat removal feature at the cold end of ASC proved to be the most challenging interface design, as it must accommodate both thermal and structural functions while achieving minimum mass. Changes made to the ASC to incorporate this design feature must also consider reliability for long-life operation. The NRA ASC rejector is an all-copper design, also serving as the pressure boundary as part of heater head assembly. It has brazed interfaces with the Inconel 625 portion of the heater head on one end and the Inconel 625 alternator transition assembly on the other end. To minimize the number of pressure vessel joints and maximize the structural integration of the design, a one-piece Inconel 718 alternator transition assembly that includes the thin-wall pressure boundary at the rejector section was devised (fig. 6). This approach replaces two pressure vessel braze joints with two thermal joints, which is considered much more reliable for long-life operation. 
To match the thermal expansion coefficient of the copper rejector, a copper-based CSAF was selected. The ideal solution is to have the CSAF brazed to the rejector section for structural and thermal integrity for long-life operation. However, to minimize the impact of the long-procurement cycle for CSAF, brazing the CSAF to the heater head has been postponed to the next build. Instead, the CSAF will be mechanically attached by interference fit to the ASC for the EU ASRG. Test articles to verify this attachment concept are being fabricated and thermal testing is planned to ensure its performance adequacy.

For synchronization and feedback control of the ASCs, a piston position sensor trade was performed. Criteria for the trade included impact on ASC and generator integration, reliability, temperature sensitivity, signal gain, and rotational tolerance. The fast linear displacement transducer (FLDT) was selected over other existing sensor types, Hall Effect sensor, and Linear Variable Differential Transformer (LVDT). The FLDT is also a heritage approach in that Sunpower has been using this sensor in other engine and cryocooler applications. An internally mounted FLDT was selected for EU ASRG over the externally mounted approach due to its $360^{\circ}$ rotation capability, decreased sensitivity to temperature, improved signal gain, and shortest generator length.

The existing ASC design uses two single pin glass-sealed hermetic feedthroughs that are welded to the transition assembly. The desire to provide redundant feedthrough terminals to improve fault tolerance and overall reliability is constrained by the need to make a significant modification to the ASC design that will not fit within the build schedule of EU ASRG. As a result, the existing glass-sealed feedthroughs are retained for EU ASRG, however, the post lug is replaced with solder lug to further enhance reliability.

Similar to SRG110 integration, the dual opposed ASCs will be mechanically attached at the alternator housings via an interconnect tube (see fig. 1). Analytical modeling of the generator in launch dynamic environments has indicated that structurally tying the housings together stabilized the ASC responses to higher frequency modes and also reduced the response of the GPHS modules. Dynamic testing of the SRG110 generator (Lewandowski, 2006) at NASA GRC has validated these analytical predictions. For EU ASRG, the ASC pressure vessel will be made from Inconel 718 to take advantage of its superior strength. The external design features going from the stand-alone ASC as shown in figure 5(b) to one that can be integrated into the EU ASRG is depicted in figure 7.

The controller is designed to be externally mounted to the generator. This approach eases generator integration and also facilitates its location to other parts of spacecraft for meeting specific mission needs. The primary functions of the controller are to provide AC/DC electrical power rectification for two independent ASC alternators, maximize power delivered to the spacecraft, and regulate the hot-end temperature by regulating the piston amplitude of the ASC within its safe operating ranges. The controller must also synchronize the two ASCs by matching their operating frequencies and phasing of piston movements to minimize the dynamic vibration imposed onto the spacecraft. In addition, the controller interfaces with the spacecraft, providing telemetry on the health status of the ASRG and receiving commands to alter the ASC operating conditions, such as setting the ASC hot-end temperature to optimize mission power.



Figure 7.-EU ASRG ASC integration features. 


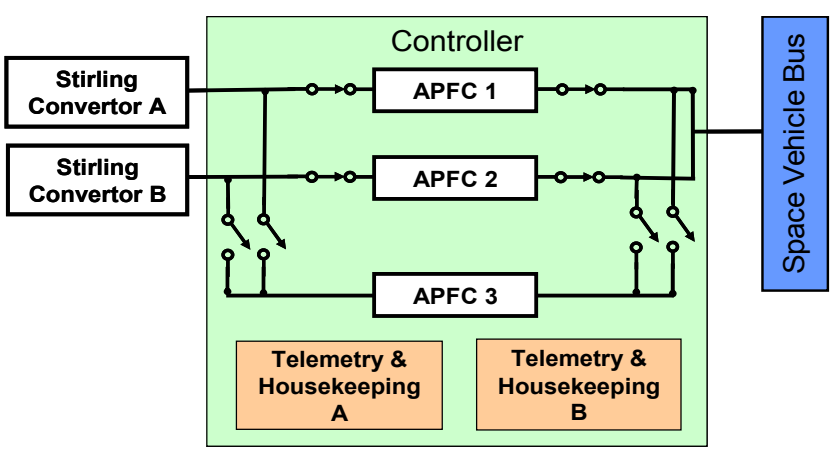

Figure 8.-Single-fault tolerant controller configuration.

The controller uses active power factor correction to cancel out the alternator inductance in converting AC power to DC. The controller is designed to be single-fault tolerant, having an $\mathrm{N}+1$ configuration with one controller card for each ASC and a third card on hot standby as illustrated in figure 8. Redundancy is also provided for telemetry and house keeping, with A and B sides typical of spacecraft design. The controller is designed and packaged in a manner that allows for its optional configuration as a fully redundant component or as a single-string component, depending on specific mission requirements.

The ASRG controller operates autonomously, requiring no intervention from the spacecraft during nominal modes. It is capable of protecting the ASRG from short-circuit fault conditions or output opencircuit conditions by dissipating all power produced by the ASCs to shunt resistors internally mounted on the generator housing. This facilitates ground operations after fueling, including during storage, transportation, and spacecraft integration at launch site.

\section{Performance}

The ASC operating efficiency and electrical power output are a function of its hot- and cold-side temperatures. The hot-side temperature is limited to $650{ }^{\circ} \mathrm{C}$ by the creep properties of Inconel 718 for 17-year operation (14-year mission life plus 3 years of fueled storage). The cold-side temperature is governed by the external environment to which the waste heat of the ASC is rejected by radiation via the generator housing and fins. Increasing the fin length can reduce the cold-side temperature and increase electrical power output, but at the expense of higher fin mass. For EU ASRG, it has been shown (fig. 3) that the generator specific power $\left(\mathrm{W}_{\mathrm{e}} / \mathrm{kg}\right)$, the criterion for component optimization and size selection, is insensitive to fin length. Thus the EU ASRG design is based on a hot and cold-side temperature of 640 and $60{ }^{\circ} \mathrm{C}$, respectively, at beginning of mission (BOM), under no-Sun conditions. A margin of $10{ }^{\circ} \mathrm{C}$ is taken on the hot-side temperature to account for temperature sensor and control electronics accuracies to ensure that $650{ }^{\circ} \mathrm{C}$ will not be exceeded.

The Microtherm HT insulation combined with the heat source support currently configured in EU ASRG is predicted to provide a 90 percent thermal efficiency, assuming a GPHS fuel inventory of $250 \mathrm{~W}_{\mathrm{t}}$ at BOM. The current EU ASC design is estimated to produce $75 \mathrm{~W}_{\mathrm{ac}}$ electrical output at the $640{ }^{\circ} \mathrm{C} / 60{ }^{\circ} \mathrm{C}$ operating temperatures. The ASC output power is limited somewhat by the generator requirement to operate over a wide temperature range throughout all mission phases, including launch ascent where the temperatures are the highest. Material substitutions for the running/seal surfaces of the ASC for better matching of thermal expansion coefficients over this wide temperature range can be made beyond EU ASRG build for further efficiency improvement. With the controller efficiency predicted at 93 percent or higher, the EU ASRG will deliver $140 \mathrm{~W}_{\mathrm{e}}$ DC output power at BOM. 
The EU ASRG mass summary at this stage of the development is shown in table 1, with beryllium end enclosures and without the connectors and harnesses used in the instrumentation end enclosures used for the electrically heated generator. Forty-two percent of the total $20.84 \mathrm{~kg}$ are from components that are either already built for EU ASRG, such as the outboard housing, fins, heat source supports, PRD and GMV, or are measured from fabricated components of identical design, such as the GPHS modules and some parts of ASC. The majority of the remaining 58 percent of the generator mass were calculated from design drawings.

TABLE 1.-EU ASRG MASS SUMMARY

\begin{tabular}{|l|c|}
\hline \multicolumn{1}{|c|}{ Component } & $\begin{array}{c}\text { Mass } \\
(\mathrm{kg})\end{array}$ \\
\hline Housing, end enclosures, and fins & 5.49 \\
\hline GHPS modules & 3.20 \\
\hline ASC & 2.61 \\
\hline Heat source supports & 0.47 \\
\hline Thermal insulation & 2.87 \\
\hline Heat collector, CSAF, and Interconnect tube & 1.96 \\
\hline PRD, GMV, Shunt, Connectors, and Harnesses & 1.35 \\
\hline Controller & 2.36 \\
\hline Hardware and misc. & 0.53 \\
\hline Total & 20.84 \\
\hline
\end{tabular}

With a $140 \mathrm{~W}_{\mathrm{e}}$ power output and a generator mass of $20.84 \mathrm{~kg}$, the EU ASRG as currently being designed and built will achieve a specific power of $6.7 \mathrm{~W} / \mathrm{kg}$, as compared to $3.4 \mathrm{~W}_{\mathrm{e}} / \mathrm{kg}$ for SRG110 design and $5.1 \mathrm{~W}_{\mathrm{e}} / \mathrm{kg}$ for GPHS-RTG. While the value of $6.7 \mathrm{~W}_{\mathrm{e}} / \mathrm{kg}$ for the EU ASRG is a substantial improvement in specific power, it reflects the value for the EU program phase. Flight system design for ASRG will further increase this value, as discussed in the next section. The ASRG team is progressing toward meeting the objective of the redirected DOE program in hardware demonstration of an EU that will improve the generator specific power for future radioisotope power system (RPS)-enabled space missions.

\section{ASRG Flight Unit Specific Power}

The achievement of a $6.7 \mathrm{~W}_{\mathrm{e}} / \mathrm{kg}$ EU ASRG specific power is constrained by the current programmatic need to use existing hardware. Consequently the overall design approach of the EU ASRG does not take advantage of the smaller size and higher temperature capability afforded by the NASA NRA ASC development. Higher specific power and reliable RPS with reduced radioisotope fuel use is always desirable. Mass savings in the power system will allow more science payload and enhance the mission. It is expected that the specific power of a flight generator based on the EU ASRG can further be improved to $>7 \mathrm{~W}_{\mathrm{e}} / \mathrm{kg}$ by optimizing the existing generator housing and end enclosure designs.

No decision has been made by NASA or DOE with respect to the design changes that will be incorporated for flight generator development beyond the EU ASRG effort. However, for potential missions that have been postulated with RPS-based electric propulsion (Fiehler and Oleson, 2004), a combination of higher power output and lower generator mass will be needed to further increase the specific power. The use of MarM-247 as the heater head material, instead of Inconel 718, will be the first step towards achieving higher power output. Sunpower has demonstrated 38 percent conversion efficiency operating at $850^{\circ} \mathrm{C}$ hot-end and $90{ }^{\circ} \mathrm{C}$ cold-end temperatures (temperature ratio of 3.1) (Wood, $2006 \mathrm{~b}$ ). The higher rejection temperature allows for less radiator surface area, which translates to lower mass for the generator housing and radiator fin combination. Trade-offs will need to be performed to optimize the desired heat rejection temperature for maximum $\mathrm{W}_{\mathrm{e}} / \mathrm{kg}$. 
A more efficient thermal insulation packaging design will be required in order to maximize the available thermal energy from the GPHS for power conversion, if the ASC is to operate at $850{ }^{\circ} \mathrm{C}$ temperature. With the bulk insulation design, such as the Microtherm HT or aerogel, the insulation must be increased from the current thickness of $1.5 \mathrm{in}$. This not only adds insulation mass but also increases the housing mass required to contain the larger insulation envelope. Again, trade-offs will have to be made to optimize the design selection of hot-end temperature, thermal loss and mass.

As seen in table 1, the generator housing, end enclosure, and fins account for over 25 percent of the EU ASRG mass, even with beryllium as the material. The existing housing design is oversized for the much smaller ASC envelope. At the hot ends of the generator, the housing dimensions are governed by GPHS and thermal insulation thickness. The housing surrounding the alternator portion of the ASC can be reduced to allow for a shorter conduction path for the ASC waste heat to the housing for a higher radiation temperature. A cylindrical rather than square cross-section housing could also lower the mass by reducing the axial and lateral ribs required for internal inert gas pressure containment.

With the MLI as thermal insulation that is capable of maintaining a 90 percent or higher thermal efficiency at $850{ }^{\circ} \mathrm{C}$ operating temperature, a generator power output of $160 \mathrm{~W}_{\mathrm{e}}$ can be expected, assuming a cold-end temperature of $90^{\circ} \mathrm{C}$ rather than the $60^{\circ} \mathrm{C}$ for the EU ASRG. With a smaller square cross-section or cylindrical housing geometry, the mass saving in the housing and the thermal insulation is estimated to be at least $3.0 \mathrm{~kg}$, while keeping the remaining components of the generator the same as in EU ASRG. These changes translate to a specific power increase from $6.7 \mathrm{~W}_{\mathrm{e}} / \mathrm{kg}$ for EU ASRG to nearly $9.0 \mathrm{~W}_{\mathrm{e}} / \mathrm{kg}$ for a potential flight unit generator. With this high specific power, coupled with a 4-fold reduction in $\mathrm{PuO}_{2}$ fuel consumption, the ASRG will fulfill the need for a multitude of future NASA missions.

\section{References}

Cockfield, R.D. and Chan, T.S., "Stirling Radioisotope Generator for Mars Surface and Deep Space Missions," in proceedings of the 37th Intersociety Energy Conversion Engineering Conference (IECEC), American Institute of Aeronautics and Astronautics, Washington, D.C., 2002, Paper no. 20188.

Fiehler, D. and Oleson, S., "Radioisotope Electric Propulsion Missions Utilizing a Common Spacecraft Design,”NASA/TM-2004-213357, NASA Glenn Research Center, Cleveland, OH, 2004.

Lewandowski, E., Callahan, J., Suarez, V, and Goodnight, T., "SRG110 Stirling Generator Dynamic Simulator Vibration Test Results and Analysis Correlation," in the proceedings of the 4th International Energy Conversion Engineering Conference and Exhibit (IECEC), American Institute of Aeronautics and Astronautics, San Diego, CA, 2006, Paper no. 4063.

Misra, A.J., "Overview of NASA Program on Development of Radioisotope Power Systems with High Specific Power," in proceedings of the 4th International Energy Conversion Engineering Conference and Exhibit (IECEC), American Institute of Aeronautics and Astronautics, San Diego, CA, 2006, Paper no. 4187.

Wong, W.A., Anderson, D.J., Tuttle, K., and Tew, R.C., "Status of NASA's Advanced Radioisotope Power Conversion Technology Research and Development," in proceedings of Space Technology and Applications International Forum (STAIF 2006), edited by M.S. El-Genk, American Institute of Physics 813, Melville, New York, 2006, pp. 340-347.

Wood, J.G., et al., "Advanced Stirling Convertor Update," in proceedings of Space Technology and Applications International Forum (STAIF 2006), edited by M.S. El-Genk, American Institute of Physics 813, Melville, New York, 2006a, pp. 640-652.

Wood, J.G., et al., "Advanced Stirling Convertor Phase II Achievements and Planned Phase III Efforts," in proceedings of the 4th International Energy Conversion Engineering Conference and Exhibit (IECEC), American Institute of Aeronautics and Astronautics, San Diego, CA, 2006b, Paper no. 4108. 


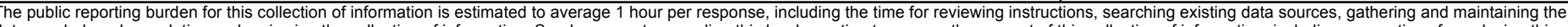

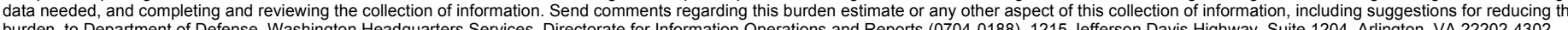

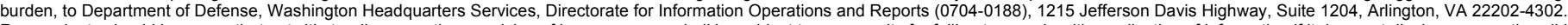

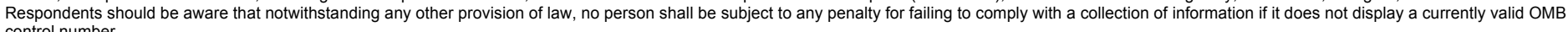

control number.
PLEASE DO NOT RETURN YOUR FORM TO THE ABOVE ADDRESS.
1. REPORT DATE (DD-MM-YYYY)
2. REPORT TYPE

14-05-2007

Technical Memorandum

\section{TITLE AND SUBTITLE}

Radioisotope Generator for Space

Development of Advanced Stirling Radioisotope Generator for Space

Exploration

3. DATES COVERED (From - To)

5a. CONTRACT NUMBER

5b. GRANT NUMBER

5c. PROGRAM ELEMENT NUMBER

5d. PROJECT NUMBER

Chan, Jack; Wood, J., Gary; Schreiber, Jeffrey, G. 5e. TASK NUMBER

5f. WORK UNIT NUMBER

WBS 138494.04.01.01

\section{PERFORMING ORGANIZATION NAME(S) AND ADDRESS(ES)}

National Aeronautics and Space Administration

John H. Glenn Research Center at Lewis Field

8. PERFORMING ORGANIZATION

REPORT NUMBER

E-15939

Cleveland, Ohio 44135-319

\section{SPONSORING/MONITORING AGENCY NAME(S) AND ADDRESS(ES)}

National Aeronautics and Space Administration

Washington, DC 20546-0001

\section{SPONSORING/MONITORS ACRONYM(S) \\ NASA}

11. SPONSORING/MONITORING REPORT NUMBER

NASA/TM-2007-214806

\section{DISTRIBUTION/AVAILABILITY STATEMENT}

Unclassified-Unlimited

Subject Category: 20

Available electronically at http://gltrs.grc.nasa.gov

This publication is available from the NASA Center for AeroSpace Information, 301-621-0390

\section{SUPPLEMENTARY NOTES}

\section{ABSTRACT}

Under the joint sponsorship of the Department of Energy and NASA, a radioisotope power system utilizing Stirling power conversion technology is being developed for potential future space missions. The higher conversion efficiency of the Stirling cycle compared with that of Radioisotope Thermoelectric Generators (RTGs) used in previous missions (Viking, Pioneer, Voyager, Galileo, Ulysses, Cassini, and New Horizons) offers the advantage of a four-fold reduction in $\mathrm{PuO}_{2}$ fuel, thereby saving cost and reducing radiation exposure to support personnel. With the advancement of state-of-the-art Stirling technology development under the NASA Research Announcement (NRA) project, the Stirling Radioisotope Generator program has evolved to incorporate the advanced Stirling convertor (ASC), provided by Sunpower, into an engineering unit. Due to the reduced envelope and lighter mass of the ASC compared to the previous Stirling convertor, the specific power of the flight generator is projected to increase from 3.5 to $7 \mathrm{~W} / \mathrm{kg}$, along with a 25 percent reduction in generator length. Modifications are being made to the ASC design to incorporate features for thermal, mechanical, and electrical integration with the engineering unit. These include the heat collector for hot end interface, cold-side flange for waste heat removal and structural attachment, and piston position sensor for ASC control and power factor correction. A single-fault tolerant, active power factor correction controller is used to synchronize the Stirling convertors, condition the electrical power from AC to DC, and to control the ASCs to maintain operation within temperature and piston stroke limits. Development activities at Sunpower and NASA Glenn Research Center (GRC) are also being conducted on the ASC to demonstrate the capability for long life, high reliability, and flight qualification needed for use in future missions.

\section{SUBJECT TERMS}

Stirling; Engine; Convertor; Radioisotope power; Generator; Controller

\begin{tabular}{|c|c|c|c|c|}
\hline \multicolumn{3}{|c|}{ 16. SECURITY CLASSIFICATION OF: } & \multirow{2}{*}{$\begin{array}{l}\text { 17. LIMITATION OF } \\
\text { ABSTRACT }\end{array}$} & \multirow{2}{*}{$\begin{array}{l}\text { 18. NUMBER } \\
\text { OF } \\
\text { PAGES } \\
16\end{array}$} \\
\hline $\begin{array}{l}\text { a. REPORT } \\
U\end{array}$ & $\begin{array}{l}\text { b. ABSTRACT } \\
U\end{array}$ & $\begin{array}{l}\text { c. THIS } \\
\text { PAGE } \\
\text { U }\end{array}$ & & \\
\hline
\end{tabular}

19a. NAME OF RESPONSIBLE PERSON Jeffrey G. Schreiber 19b. TELEPHONE NUMBER (include area code) 216-433-6144 

